\title{
Correction to: Meta-Review on the Effectiveness of Classroom-Based Psychological Interventions Aimed at Improving Student Mental Health and Well-Being, and Preventing Mental IIlness
}

\section{Barbora Šouláková ${ }^{1}$ (D) A Alexandr Kasal ${ }^{1,4} \cdot$ Bethany Butzer $^{2,1} \cdot$ Petr Winkler $^{1,3}$}

Published online: 27 June 2019

(C) Springer Science+Business Media, LLC, part of Springer Nature 2019

\section{Correction to: The Journal of Primary Prevention (2019) 40:255-278 https://doi.org/10.1007/s10935-019-00552-5}

The original version of the article, unfortunately, missing the funding information. Funding note is given below.

Funding This work was supported by MSMT within the national action plan (NPU), LO1611.

Publisher's Note Springer Nature remains neutral with regard to jurisdictional claims in published maps and institutional affiliations.

The original article can be found online at https://doi.org/10.1007/s10935-019-00552-5.

\section{Barbora Šouláková}

Barbora.Soulakova@nudz.cz

1 Department of Social Psychiatry, National Institute of Mental Health, Topolová 748, 25067 Klecany, Czech Republic

2 School of Psychology, University of New York in Prague, Prague, Czech Republic

3 Centre for Global Mental Health, Institute of Psychiatry, Psychology and Neuroscience, King's College London, London, UK

4 Faculty of Social Sciences, Charles University in Prague, Prague, Czech Republic 